\title{
Forceps biopsy and suction catheter for sampling in pulmonary nodules and infiltrates
}

\author{
Antje Peschke*, Bärbel Wiedemann\#, Gert Höffken, ${ }^{\star{ }^{\star ๘}}$ and Dirk Koschel*
}

ABSTRACT: Transbronchial lung biopsy with forceps is a standard procedure in bronchoscopic tissue sampling. Suction catheter aspiration is another technique, but it is not widely known and almost no data exist regarding its diagnostic efficiency.

272 patients were included in a prospective and randomised study between February 2007 and October 2009. All were referred for bronchoscopic evaluation of pulmonary nodules/masses or infiltrates. We compared the diagnostic yield of forceps biopsy and suction catheter aspiration for a definite diagnosis and looked at whether such a diagnosis depends on the underlying pulmonary change.

All patients underwent bronchoscopy with forceps biopsy and catheter aspiration. A definitive diagnosis was reached in a total of $183(67.3 \%)$ patients, with catheter aspiration in 140 (51.5\%) patients and with forceps biopsy in 136 (50.0\%) patients. In 90 (33.1\%) patients, a definite diagnosis could only be reached with the combination of both techniques. The diagnostic yield of forceps biopsy was better than catheter aspiration in infiltrates $(p=0.027)$, but was no different in nodules or masses $(p=0.09)$.

Suction catheter aspiration is a useful technique of bronchoscopic tissue sampling. The combination of catheter aspiration and forceps biopsy results in a higher diagnostic yield than either method used alone.

KEYWORDS: Bronchoscopy, catheter aspiration, forceps biopsy, pulmonary infiltrates, pulmonary nodules, transbronchial biopsy

B ronchoscopy is a standard diagnostic procedure in the evaluation of peripheral pulmonary nodules or masses, as well as lung infiltrates. A universal method of bronchoscopic tissue sampling in endobronchial not visible peripheral pulmonary lesions is transbronchial biopsy with forceps [1-3]. Usually, the procedure is performed with fluoroscopy guidance and with a low complication rate [4]. Other common sampling techniques are transbronchial needle aspiration [5] and bronchial brushings [6]. Suction catheter aspiration is another, not widely known, method which was described in 1964 by FRIEDEL [7]. Only a few data exist regarding its diagnostic efficiency in peripheral pulmonary lesions $[8,9]$, but it is recommended as a diagnostic procedure in the recently published interdisciplinary guidelines of the German Respiratory Society and German Cancer Society of lung cancer [10].

The aim of the present study was to prospectively evaluate and compare the diagnostic yield of catheter aspiration with transbronchial forceps biopsy as tissue sampling techniques in peripheral pulmonary nodules or masses and lung infiltrates.

\section{MATERIAL AND METHODS \\ Subjects}

This prospective and randomised study was approved by the ethics committee of the University of Dresden, Dresden, Germany. 272 patients referred to the Dept of Pulmonary Medicine, Fachkrankenhaus Coswig, Coswig, Germany, between February 2007 and October 2009 with undiagnosed peripheral pulmonary lesions on computed tomography of the chest were included in the study after signing an ethics committeeapproved informed consent.

All chest computed tomographs were reviewed by two of the authors (A. Peschke and D. Koschel) and based on radiologist's computed tomographybased diagnosis the pulmonary lesions were divided into two groups (solid or infiltrative lesions). The size of the solid lesions (nodules or

\section{AFFILIATIONS}

*Dept of Pulmonary Diseases, Fachkrankenhaus Coswig, Centre for Pulmonary Diseases and Thoracic

Surgery, Coswig, and

\#Institute of Medical Informatics and Biometrics, University of Technology, and

"Dept of Internal Medicine I, University Hospital Carl Gustav Carus Dresden, Dresden, Germany.

\section{CORRESPONDENCE}

D. Koschel

Dept of Pulmonary Diseases,

Fachkrankenhaus Coswig

Centre for Pulmonary Diseases and

Thoracic Surgery

Neucoswiger Str. 21

01640 Coswig

Germany

E-mail: dr.koschel@

fachkrankenhaus-coswig.de

Received:

Feb 082011

Accepted after revision:

Sept 242011

First published online:

Oct 172011

European Respiratory Journal

Print ISSN 0903-1936

Online ISSN 1399-3003 
masses) were recorded by their widest diameter and were divided into three groups according to the diameter of the lesion ( $<2 \mathrm{~cm}, 2-4 \mathrm{~cm}$ and $\geqslant 4 \mathrm{~cm}$ ); patients with endobronchial visible abnormality were not included.

\section{Procedure}

All the procedures were performed by senior physicians and trained bronchoscopists in a bronchoscopy room equipped with a rotating $\mathrm{C}$-arm fluoroscope. Procedures were performed under general anaesthesia, with intubation of a rigid bronchoscope (10318 FL, $12 \mathrm{~mm}$ diameter; Karl Storz, Tuttlingen, Germany), or with local anaesthesia and sedation (midazolam i.v.). A flexible bronchoscope (FB 19; Pentax, Tokyo, Japan) was used for all diagnostic procedures. After careful examination of the bronchial tree, sampling from the peripheral pulmonary lesion under fluoroscopic guidance was performed. Tissue sampling was performed with catheter suction (Rüsch Cannula, $120 \mathrm{~cm}$ long; Rüsch, Teleflex Medical, Kernen, Germany) and with biopsy forceps (2.2 mm diameter, $120 \mathrm{~cm}$ long; MTW, Wesel, Germany). Both biopsy techniques were performed sequentially in a random order in every patient. The catheter aspiration technique included moving the catheter back and forth while continued suction was applied with a $10-\mathrm{mL}$ syringe. The biopsy forceps technique was performed in standard fashion. Both sampling techniques were conducted until a satisfactory macroscopic specimen was obtained, which was decided in each case by the bronchoscopist. From each sampling technique, at least one cytological specimen was also obtained. This was smeared on glass slides and air-dried before being transferred to the cytological laboratory of the Fachkrankenhaus Coswig where a MaiGrünwald-Giemsa staining was performed. The histological specimens were grounded in formalin before sending them to an independent pathological laboratory (O. Holotiuk, Institute of Pathology, Dresden, Germany) cooperating with the Fachkrankenhaus Coswig.

All patients had a chest radiograph taken $3-4 \mathrm{~h}$ after the bronchoscopy to evaluate iatrogenic pneumothorax.

Data relating to pulmonary lesion characteristics, diagnostic yield and safety were recorded and analysed. Bleeding was judged clinically by the need for clinical intervention as light, moderate or severe [11].

\section{Statistical analysis}

The data were expressed as mean $\pm \mathrm{SD}$ and range or as absolute or relative frequency. The diagnostic yield of forceps biopsy and catheter aspiration was compared using the McNemar test for correlated dichotomous responses. The proportion of the diagnostic yield between procedures under general and local anaesthesia were analysed by Chi-squared tests. All p-values reported are from explorative two-sided tests and regarded as statistically significant if $\mathrm{p}<0.05$.

Statistical analysis was performed using statistical software SPSS (Version 17.01; SPSS Inc., Chicago, IL, USA).

\section{RESULTS}

\section{Patient demographics and lesion characteristics}

196 males and 76 females with a mean age of $68.4 \pm 9.9$ yrs (range 36-89 yrs) were examined. The characterisation of the chest computed tomography resulted in 216 (79.4\%) solid pulmonary lesions (nodules and masses) and $56(20.6 \%)$ infiltrates. Of the solid pulmonary lesions 14 (6.5\%) were $<2 \mathrm{~cm}$ in diameter, $93(43.1 \%)$ between 2 and $4 \mathrm{~cm}$, and 109 $(50.4 \%)>4 \mathrm{~cm}$ in diameter.

$69(25.4 \%)$ lesions showed pleural contact and $24(8.8 \%)$ mediastinal contact.

\section{Diagnosis}

Of the 272 cases enrolled in the study, a definitive cytohistological diagnosis was made on 235 lesions (86.4\%), 183 (67.3\%) through bronchoscopic tissue sampling with biopsy forceps and/or catheter suction, and 52 (19.1\%) through other diagnostic procedures, such as repeat bronchoscopy, transbronchial needle aspiration, transthoracic needle aspiration, endosonographic needle aspiration, and surgery or microbiological examination of specimens. Malignancy was established in $133(73.7 \%)$ and benign disorders in $63(27.3 \%)$ cases. In 37 $(13.6 \%)$ cases, a definite diagnosis was not made, either because the patient refused further examination with definite pathological confirmation or because spontaneous regression was observed at control. All diagnoses obtained by forceps biopsy and/or catheter aspiration are reported in table 1 ; those obtained by other diagnostic procedures are reported in table 2. Final diagnoses of solid lesions and infiltrative lesions are reported in table 3 .

\section{Diagnostic yield}

All patients underwent a bronchoscopy with forceps biopsy and catheter aspiration as tissue sampling techniques. The overall diagnostic yield is presented in table 4. A definite diagnosis was reached in a total of $183(67.2 \%)$ patients, with catheter aspiration in $140(51.5 \%)$ patients and with forceps biopsy in $136(50.0 \%)$ patients. In 90 (33.1\%) patients, a definite diagnosis could be reached only with the combination of both techniques.

\begin{tabular}{|c|c|c|c|}
\hline Diagnosis & $\begin{array}{l}\text { Forceps biopsy } \\
\text { and catheter } \\
\text { aspiration }\end{array}$ & $\begin{array}{c}\text { Only forceps } \\
\text { biopsy }\end{array}$ & $\begin{array}{l}\text { Only catheter } \\
\text { aspiration }\end{array}$ \\
\hline Malignant lesions & 65 & 28 & 40 \\
\hline NSCLC & 53 & 26 & 37 \\
\hline SCLC & 7 & 0 & 1 \\
\hline Metastasis & 5 & 2 & 2 \\
\hline Benign lesions & 28 & 15 & 7 \\
\hline Pneumonia & 16 & 5 & 5 \\
\hline Granulomatosis & 2 & 3 & 1 \\
\hline $\mathrm{COP}$ & 3 & 5 & 0 \\
\hline Others ${ }^{\#}$ & 7 & 2 & 1 \\
\hline
\end{tabular}




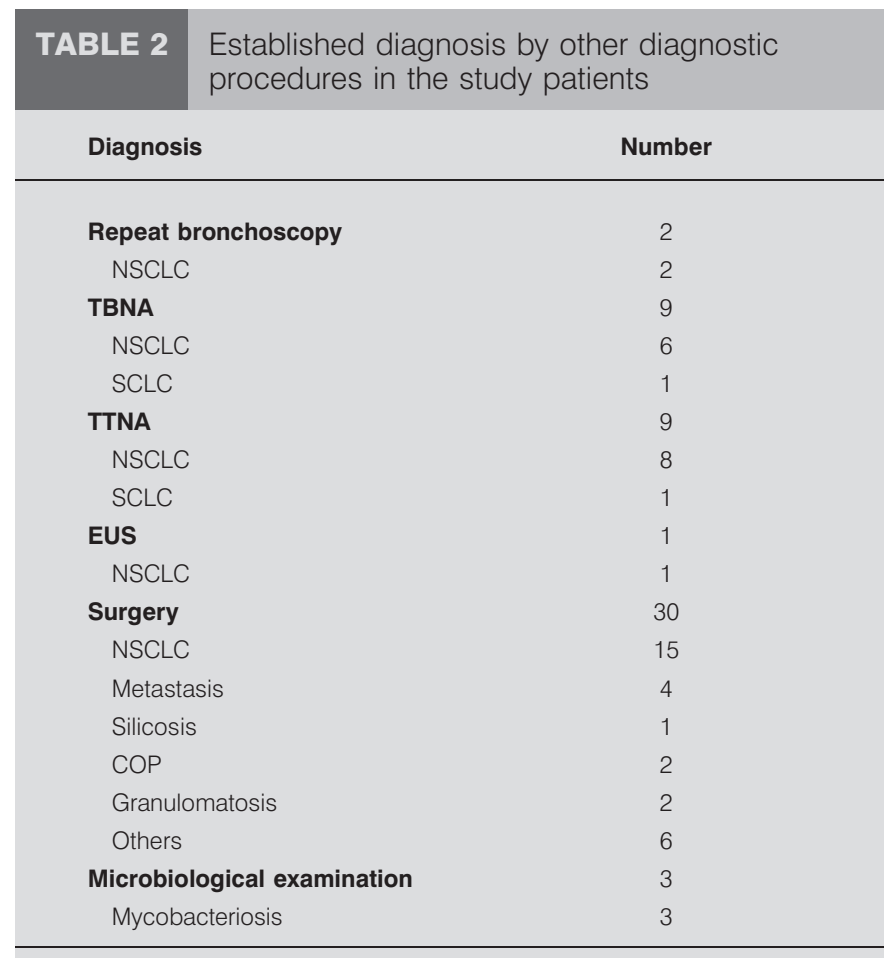

NSCLC: nonsmall cell lung cancer; TBNA: transbronchial needle aspiration; SCLC: small cell lung cancer; TTNA: transthoracal needle aspiration; EUS: endo-oesophageal ultrasound; COP: crytogenic organising pneumonia.

Table 5 shows the diagnostic yields associated with the radiological signs of the pulmonary lesions.

The diagnostic yield of forceps biopsy was better than catheter aspiration $(53.6 \%$ versus $33.9 \%, p=0.027)$ in pulmonary infiltrates. In solid pulmonary lesions, there was a nonsignificant trend for catheter aspiration to be better than forceps biopsy $(56.0 \%$ versus $49.1 \%, \mathrm{p}=0.091)$. With regard to the size of the solid pulmonary lesions, there were no significant differences of the diagnostic yield between forceps biopsy and

\begin{tabular}{lcc} 
TABLE 3 & $\begin{array}{l}\text { Established diagnosis of solid lesions or lung } \\
\text { infiltrations in the study patients }\end{array}$ \\
Diagnosis & Solid lesions & Infiltrative lesions \\
\hline Malignant lesions & 126 & 7 \\
NSCLC & 111 & 5 \\
SCLC & 8 & 0 \\
Metastasis & 7 & 2 \\
Benign lesions & 20 & 29 \\
Pneumonia & 7 & 19 \\
Granulomatosis & 0 & 8 \\
COP & 2 & 4 \\
Others & 8 & 2 \\
\hline
\end{tabular}

NSCLC: nonsmall cell lung cancer; SCLC: small cell lung cancer; COP: crytogenic organising pneumonia. *: including actinomycosis, aspergillosis and eosinophilic infiltrates.
TABLE 4 Diagnostic yield of different bronchoscopic sampling techniques in the study patients

$\begin{array}{lc}\text { Definite diagnosis } & 235(86.4) \\ \text { With bronchoscopy (CA and/or FB) } & 183(67.3) \\ \text { With CA } & 140(51.5) \\ \text { With FB } & 136(50.0) \\ \text { With CA or FB } & 90(33.1) \\ \text { With other sampling techniques }{ }^{\#} & 52(19.1) \\ \text { No definitive diagnosis } & 37(13.6)\end{array}$

Data are presented as n (\%). CA: catheter aspiration; FB: forceps biopsy. ${ }^{*}$ : rebronchoscopy, transbronchial needle aspiration, transthoracal needle aspiration, endo-oesophageal sonography, surgery, etc.

catheter aspiration $(<2 \mathrm{~cm}, 35.7 \%$ versus $35.7 \%, \mathrm{p}=1.0 ; 2-4 \mathrm{~cm}$, $41.9 \%$ versus $51.6 \%, \mathrm{p}=0.122 ;>4 \mathrm{~cm}, 56.9 \%$ versus $62.4 \%$, $\mathrm{p}=0.418$ ). Looking at the localisation of the pulmonary lesion, there were no significant differences in the diagnostic yield of forceps biopsy and catheter aspiration, whether there was a pleural contact $(52.2 \%$ versus $47.8 \%, \mathrm{p}=0.664)$ or not $(49.3 \%$ versus $52.7 \%, \mathrm{p}=0.47$ ) and whether there was a mediastinal contact $(54.2 \%$ versus $58.3 \%, \mathrm{p}=1.0)$ or not $(49.6 \%$ versus $50.8 \%$, $\mathrm{p}=0.826)$.

There was no significant difference in the diagnostic yield with regard to malignant $(p=0.182)$ or benign lesions $(p=0.134)$ when comparing catheter aspiration and forceps biopsy (table 6).

$51.8 \%$ of the bronchoscopies were performed under local anaesthesia and $48.2 \%$ under general anaesthesia. There was no significant difference in the diagnostic yield between the bronchoscopic procedures performed under local or general anaesthesia at all (54.1\% versus $45.9 \%, \mathrm{p}=0.285)$, either for catheter aspiration ( $53.6 \%$ versus $46.4 \%, \mathrm{p}=0.556$ ) or for forceps biopsy ( $52.2 \%$ versus $47.8 \%, \mathrm{p}=0.903)$ alone.

\begin{tabular}{|c|c|c|c|c|}
\hline \multirow[t]{3}{*}{ TABLE 5} & \multicolumn{4}{|c|}{$\begin{array}{l}\text { Diagnostic yield of the two different } \\
\text { bronchoscopic sampling techniques associated } \\
\text { with radiological signs and location of pulmonary } \\
\text { lesions }\end{array}$} \\
\hline & & \multicolumn{2}{|c|}{ Diagnostic yield } & \multirow[t]{2}{*}{ p-value } \\
\hline & & CA & FB & \\
\hline \multicolumn{2}{|c|}{ Pulmonary nodules and masses } & 56.0 & 49.1 & NS \\
\hline \multicolumn{2}{|l|}{$<2 \mathrm{~cm}$} & 35.7 & 35.7 & NS \\
\hline \multicolumn{2}{|l|}{$2-4 \mathrm{~cm}$} & 51.6 & 41.9 & NS \\
\hline \multicolumn{2}{|l|}{$>4 \mathrm{~cm}$} & 62.4 & 56.9 & NS \\
\hline \multicolumn{2}{|c|}{ Pulmonary infiltrates } & 33.9 & 53.6 & 0.027 \\
\hline \multicolumn{2}{|c|}{ Pleural contact } & 47.8 & 52.2 & NS \\
\hline \multicolumn{2}{|c|}{ Mediastinal contact } & 58.3 & 54.2 & NS \\
\hline
\end{tabular}

Data are presented as \%, unless otherwise stated. CA: catheter aspiration; FB: forceps biopsy; Ns: nonsignificant. 


\begin{tabular}{|c|c|c|c|c|}
\hline \multirow[t]{3}{*}{ TABLE 6} & \multicolumn{4}{|c|}{$\begin{array}{l}\text { Diagnostic yield of the two different } \\
\text { bronchoscopic sampling techniques associated } \\
\text { with the dignity (i.e. whether the lesions are } \\
\text { malignant or benign) of pulmonary lesions }\end{array}$} \\
\hline & & \multicolumn{2}{|c|}{ Diagnostic yield } & \multirow[t]{2}{*}{$\mathrm{p}$-value } \\
\hline & & CA & FB & \\
\hline \multicolumn{2}{|c|}{ Malignant lesions } & 78.9 & 69.9 & NS \\
\hline \multicolumn{2}{|c|}{ Benign lesions } & 70.0 & 86.0 & NS \\
\hline
\end{tabular}

\section{Complications}

Mild bleeding was observed in 12 cases (4.4\%) with catheter aspiration and 38 cases $(14.0 \%)$ with forceps biopsy $(\mathrm{p}<0.05)$. Moderate or severe bleeding was not observed in this study, and no pneumothorax or deaths occurred with the diagnostic procedures.

\section{DISCUSSION}

In this prospective, randomised study of 272 patients with pulmonary peripheral lesions comparing suction catheter aspiration with forceps biopsy as the standard procedure of bronchoscopic tissue sampling, the diagnostic yield was $51.5 \%$ with catheter aspiration and 50.0\% with forceps biopsy. The diagnostic yield increased to an overall diagnostic yield of $67.3 \%$ using both tissue sampling procedures.

The diagnostic yield of fluoroscopy-guided forceps biopsy depends on the size and dignity (i.e. whether the lesions are malignant or benign) of the lesion and varies widely. In 91 patients meeting the criteria of a stage I carcinoma and only $13 \%$ of benign lesions, TORRINGTON and KERN [12] reported a diagnostic yield of $18 \%$. If the criterion of the nodule size was $<4 \mathrm{~cm}$, the range of the diagnostic yield was between 19 and $61 \%$ [13-16], and nodule size $<6 \mathrm{~cm}$ gave a diagnostic yield between 36 and $62 \%$ [14, 17]. Our overall diagnostic yield of forceps biopsy matches these results from previously published reports.

There are only two reports about studies using catheter aspiration as a bronchoscopic tissue sampling method. In a prospective study with 28 patients, FRANKE et al. [8] compared the diagnostic yield of catheter aspiration and forceps biopsy concerning malignancy in patients with peripheral lung nodules with a tumour size of $41.4 \pm 14.5 \mathrm{~mm}$. Catheter aspiration was significantly superior to forceps biopsy $(77 \%$ compared with $50 \%$ ), and combining both procedures further improved the diagnostic yield by $\sim 10 \%$. In a recently published report, EBERHARDT et al. [9] compared suction catheter aspiration with forceps biopsy in 54 patients for the sampling of solitary pulmonary nodules guided by electromagnetic navigational bronchoscopy (ENB). The overall diagnostic yield of the two tissue sampling procedures combined with ENB was $75.5 \%$. Of the cases with a definite cytohistological diagnosis, $90 \%$ were made using catheter aspiration and only 55\% with forceps biopsy. In $45 \%$, only the specimens obtained from catheter aspiration were positive.
The authors stated that catheter aspiration combined with forceps biopsy improves the diagnostic yield after ENB in small peripheral lesions. The diagnostic yield of ENB varied between $62.5 \%$ [18] and $74 \%$ in other settings [19], and when combined with radial endobronchial ultrasound was reported to be up to $88 \%$ [20]. Therefore, ENB can enhance the diagnostic yield of bronchoscopic tissue sampling in peripheral lung lesions independently of lesion size. This should be weighed against the significant higher costs of the equipment and the disposables [9].

We found a significant difference in the diagnostic yield of the two biopsy procedures in pulmonary infiltrates, for which forceps biopsy was superior to catheter aspiration $(p=0.027)$. This could be due to the ability of the biopsy forceps to sample more alveolar tissue, whereas the suction catheter reaches only lesions with intrabronchial findings, such as bronchial carcinomas or bronchiolitis obliterans with organising pneumonia.

We thought that the different stiffness of the two biopsy materials with the softness of the suction catheter and the rigidity of the biopsy forceps might mean that the diagnostic yield would be associated with the location of the pulmonary lesion. Reaching the subpleural space with the soft suction catheter could be difficult, as could reaching lesions with mediastinal contact with the biopsy forceps. However, we found no significant difference between the two biopsy procedures, irrespective of the localisation of the pulmonary lesion.

A few limitations to our investigation should be noted. We did not define how many biopsies with forceps had to be performed or how often the suction catheter had to be moved back and forth. The decision to stop the tissue sampling was made by the bronchoscopist once a satisfactory macroscopic specimen had been obtained. With regard to the overall diagnostic yield, which was in the range of other published studies, and the low complication rate, we think this individual decision is superior to a fixed study schedule of, for example, taking at least four specimens with the forceps. Likewise, bronchoscopy in local or general anaesthesia was at the discretion of the responsible bronchoscopist and one could assume that the diagnostic yield is influenced by this decision mainly due to lack of perfect patient cooperation in local anaesthesia bronchoscopies. Interestingly, we found no significant difference in the diagnostic yield between the bronchoscopic procedures performed under local or general anaesthesia. Another limitation is that both methods were applied in the same patient, even though they were applied sequentially and at random. Therefore, a bias cannot be excluded, as the localisation of the lesion may have been established by the respective first method.

In summary, we have found that suction catheter aspiration is a useful and safe technique of bronchoscopic tissue sampling in pulmonary nodules/masses and infiltrates. Forceps biopsy is superior only in lung infiltrates. Catheter aspiration and transbronchial biopsies with forceps should be performed in all patients to give the best diagnostic yield. 


\section{STATEMENT OF INTEREST}

None declared.

\section{REFERENCES}

1 Shure D. Transbronchial biopsy and needle aspiration. Chest 1989; 95: $1130-1138$

2 Mazzone P, Jain P, Arroliga AC, et al. Bronchoscopy and needle biopsy techniques for diagnosis and staging of lung cancer. Clin Chest Med 2002; 23: 137-158.

3 Ensminger SA, Prakash USB. Is bronchoscopic lung biopsy helpful in the management of patients with diffuse lung disease? Eur Respir J 2006; 28: 1081-1084.

4 Smyth CM, Stead RJ. Survey of flexible fibreoptic bronchoscopy in the United Kingdom. Eur Respir J 2002; 19: 458-463.

5 Wang KP, Marsh BR, Summer WR, et al. Transbronchial needle aspiration for diagnosis of lung cancer. Chest 1981; 80: 48-50.

6 Cortese DA, McDougall JC. Biopsy and brushing of peripheral lung cancer with fluoroscopic guidance. Chest 1979; 75: 141-145.

7 Friedel H. Die Katheterbiopsie [The catheter biopsy]. Zeitschrift für Tuberkulose 1964; 122: 246-250.

8 Franke KJ, Nilius G, Rühle KH. Transbronchial biopsy in comparison with catheter aspiration in the diagnosis of peripheral pulmonary nodules. Pneumologie 2006; 60: 7-10.

9 Eberhardt R, Morgan RK, Ernst A, et al. Comparison of suction catheter versus forceps biopsy for sampling of solitary pulmonary nodules guided by electromagnetic navigational bronchoscopy. Respiration 2010; 79: 54-60.

10 Goeckenjan G, Sitter H, Thomas M, et al. Prevention, diagnosis, therapy, and follow-up of lung cancer. Interdisciplinary Guideline of the German Respiratory Society and the German Cancer Society. Pneumologie 2010; 64: 1-164.

11 Herth FJF, Becker HD, Ernst A. Aspirin does not increase bleeding complications after transbronchial biopsy in humans. Chest 2002; 122: 1461-1464.

12 Torrington KG, Kern JD. The utility of fiberbronchoscopy in the evaluation of solitary pulmonary nodules. Chest 1993; 104: 1021-1024.

13 Wallace JM, Deutsch AL. Flexible fiberoptic bronchoscopy and percutaneous needle lung aspiration for evaluating the solitary pulmonary nodule. Chest 1982; 81: 665-670.

14 Fletcher EC, Levin DC. Flexible fiberoptic bronchoscopy and fluoroscopically guided transbronchial biopsy in the management of solitary pulmonary nodules. West J Med 1982; 136: 477-483.

15 Baaklini WA, Reinoso MA, Gorin AB, et al. Diagnostic yield of fiberoptic bronchoscopy in evaluating solitary pulmonary nodules. Chest 2000; 117: 1049-1054.

16 Lai RS, Lee SSJ, Ting YM, et al. Diagnostic value of transbronchial lung biopsy under fluoroscopic guidance in an endemic area of tuberculosis. Respir Med 1996; 90: 139-143.

17 Gaeta M, Pandolfo I, Volta S, et al. Bronchus sign on CT in peripheral carcinoma of the lung: value in predicting results of transbronchial biopsy. Am J Roentgenol 1991; 157: 1181-1185.

18 Makris D, Scherpereel A, Leroy S, et al. Electromagnetic navigation diagnostic bronchoscopy for small peripheral lung lesions. Eur Respir J 2007; 29: 472-478.

19 Gildea TR, Mazzone PJ, Karnak D, et al. Electromagnetic navigation diagnostic bronchoscopy: a prospective study. Am J Respir Crit Care Med 2006; 174: 982-989.

20 Eberhardt R, Anantham D, Ernst A, et al. Multimodality bronchoscopic diagnosis of peripheral lung lesions: a randomized controlled trial. Am J Respir Crit Care Med 2007; 176: 36-41. 